GRASAS Y ACEITES $72(2)$

April-June 2021, e411

ISSN-L: 0017-3495

https://doi.org/10.3989/gya.0222201

\title{
Characterization of the chemical and nutritive quality of cold- pressed grape seed oils produced in the Republic of Serbia from different red and white grape varieties
}

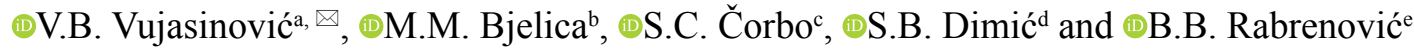 \\ ${ }^{a}$ University of Novi Sad, Faculty of Sciences, 21000 Novi Sad, Serbia \\ bUniversity of Novi Sad, Faculty of Technology, 21000 Novi Sad, Serbia \\ 'Faculty of Agriculture and Food Sciences, 71000 Sarajevo, Bosna and Herzegovina \\ ${ }^{\mathrm{d} B i m a l}$ Trading d.o.o. Beograd, 11000 Belgrade, Serbia \\ ${ }^{\mathrm{e} U n i v e r s i t y ~ o f ~ B e l g r a d e, ~ F a c u l t y ~ o f ~ A g r i c u l t u r e ~ Z e m u n, ~} 11000$ Belgrade, Serbia \\ ${ }^{\square}$ Corresponding author: vesna.vujasinovic@dgt.uns.ac.rs
}

Submitted: 27 February 2020; Accepted: 28 May 2020; Published online: 03 June 2021

\begin{abstract}
SUMMARY: Six cold-pressed oil samples obtained from the seeds of different grape varieties grown in a Fruška Gora vineyard in the Republic of Serbia were examined for chemical and nutritive quality, as well as antiradical capacity. All the tested samples were of good quality, but the results showed noticeable differences in seed oil properties for red and white grape varieties. The highest content in total tocols, $575.23 \pm 4.46 \mathrm{mg} / \mathrm{kg}$, was found in the red grape seed oil of the Merlot variety, but the vitamin E activity of white grape seed oils was significantly higher. Regarding single phenols, the most prevalent fraction in all the oil samples was ursolic acid, up to $336.3 \pm 4.8$ $\mu \mathrm{g} / \mathrm{g}$ in the grape seed oil of the Hamburg variety. The highest content in the total phenolic compounds, $54.92 \pm 0.93 \mu \mathrm{g}$ GAE/g, was detected in the oil of red grape seeds. Although significant differences existed between samples, $\mathrm{EC}_{50}$ values were the lowest for the red grape seed oils, varying from $29.84 \pm 1.07$ to $65.34 \pm 0.32 \mathrm{mg}$ oil $/ \mathrm{mg}$ DPPH, indicating that these oils had the highest antiradical capacity.
\end{abstract}

KEYWORDS: Acidity; Antiradical capacity; Grape seed oil; Phenols; Tocopherols; Totox

RESUMEN: Calidad química y nutricional de los aceites de semilla de uva prensados en frío producidos en la República de Serbia a partir de diferentes variedades de uva roja y blanca. Se examinaron seis muestras de aceite prensado en frío obtenidas de semillas de diferentes variedades de uva cultivadas en un viñedo de Fruška Gora en la República de Serbia, para determinar su calidad química y nutricional, así como su capacidad antirradicalaria. Todas las muestras analizadas fueron de buena calidad, pero los resultados mostraron propiedades de los aceites de semillas notablemente diferentes para las variedades de uva roja y blanca. El mayor contenido de tocols totales, $575,23 \pm 4,46 \mathrm{mg} / \mathrm{kg}$, se encontró en el aceite de semilla de uva roja de la variedad Merlot, pero la actividad de la vitamina E de los aceites de semilla de uva blanca fue significativamente mayor. Con respecto a los fenoles simples, la fracción prelevante en todas las muestras de aceite contenía ácido ursólico, hasta 336,3 $\pm 4,8 \mu \mathrm{g} / \mathrm{g}$ en el aceite de semilla de uva de la variedad Hamburg. El mayor contenido de los compuestos fenólicos totales, 54,92 $\pm 0,93 \mathrm{mg} \mathrm{GAE} / \mathrm{g}$, se detectó en el aceite de semillas de uva roja. Aunque existieron diferencias significativas entre las muestras, los valores de EC50 fueron más bajos para los aceites de semilla de uva roja, variando de $29,84 \pm 1,07$ a $65,34 \pm 0,32 \mathrm{mg}$ de aceite/mg de DPPH, lo que indica que estos aceites tenían la mayor capacidad antirradicalaria.

PALABRAS CLAVE: Aceite de semilla de uva; Acidez; Capacidad antirradicalaria; Fenoles; Tocoferoles; Totox

Citation/Cómo citar este artículo: Vujasinović VB, Bjelica MM, Čorbo SC, Dimić BS, Rabrenović BB. 2021. Characterization of the chemical and nutritive quality of cold-pressed grape seed oils produced in the Republic of Serbia from different red and white grape varieties. Grasas Aceites 72 (2), e411. https://doi.org/10.3989/gya.0222201

Copyright: (C2021 CSIC. This is an open-access article distributed under the terms of the Creative Commons Attribution 4.0 International (CC BY 4.0) License. 


\section{INTRODUCTION}

The use of by-products from various food and beverage technologies, including the processing of grapes, has become a necessity in terms of producing a new product instead of creating waste. The utilization of by-products has also become an integral part of the regular production process, both due to increased processing efficiency and energy consumption. Grapes are one of the most extensively cultivated crops in the world with a global production of around 74 million tonnes produced worldwide from a production area of about 6.9 million ha. About $75 \%$ of total grape cultivation is used for wine production. Europe produced 23.7 million tonnes of grapes in 2017, which amounts to $34.9 \%$ of the total world production. Grape production is mostly concentrated in moderately warm climatic zones, such as Italy (7.17 million tonnes), France (5.92 million tonnes) and Spain (5.39 million tonnes) in 2017 (FAOSTAT, 2018).

Viniculture is a very important activity in the field of agricultural production in the Republic of Serbia. The total area under grapevine crops is $22,149.97$ ha. Natural potential, climate conditions, tradition, as well as the subsidizing of new wine planting will allow further consolidation of viniculture and winemaking. According to the National Statistics Office of Serbia, grape production in 2018 was 149.595 tonnes (Jakšić et al., 2019).

Grape seed oil (mainly solvent extracted and subsequently refined), has been produced for decades, and is gaining market prevalence as a gourmet oil (Dwyer et al., 2014). Nowadays, however, the cold-pressing process is preferred for the extraction of oil from plant seeds, to a conventional process in which oil extraction is carried out by organic solvents. Since there are no processing steps that would allow for the removal of undesired contaminants from the oil in producing coldpressed, i.e. edible non-refined oils, high quality of the raw material is required (Mätthaus and Spener, 2008). Also, the cold-pressing process ensures the maximum retention of bioactive compounds, such as essential fatty acids, phenols and flavonoids, tocopherols, and the like (Teh and Birch, 2013; Radočaj and Dimić, 2013).

Grape seed oil has recently become of great interest for two reasons: first, the oil extraction from seeds contributes to reducing the problem of waste from the processing of grapes; second, nutritionists increasingly recommend the consumption of this oil for its unsaturated fatty acids, phenolic compounds, tocopherols, pigments and low cholesterol content. These minor fractions play a very important role in determining the nutritional and health impact of this seed and its oil (Pardo et al., 2009; Garavaglia et al., 2016, Cicero et al., 2018; Unusan, 2020).

The most important compounds, based on which the nutritive value of grape seed oil is examined, are various biologically active components. These ingredients, although present in very small amounts in oil, have a high metabolic value in the body, showing antioxidant, antiradical and vitamin activity -all different health protective effects (Fernandes et al., 2013; Fagundes Assumpção et al., 2015; Dabetic et al., 2020). An important argument for the use of grape seed oil in medical terms is the high contents in the oligomeric phenolic compounds in this oil (Matthäus, 2008). Bioactive components are of great importance for the application of oils to food and pharmaceutical industries due to their antilipid, anticancer and antimutagenic effects, as well as for reducing the risk of cardiovascular diseases (Garavaglia et al., 2016; Shinagawa et al, 2015).

Moreover, it is worth mentioning that an edible oil's qualitative and quantitative composition widely depends not only on botanical species, but also on soil characteristics, agronomic and climatic conditions, seed quality, ripening stage, oil extraction process and storage procedure (Dwyer et al., 2014; Cicero et al., 2018).

Since cold-pressed grape seed oil is becoming very popular, compared to refined oil, the aim of this study was to characterize some quality parameters and the nutritive profile of cold-pressed grape seed oils obtained from different red and white grape varieties. Since the oil's quality depends on agronomic and climatic diversity, results obtained by investigations of cold-pressed grape seed oils produced in the Republic of Serbia from Fruška Gora vineyards are presented here. To the best of our knowledge, until now, there was only very limited, published data on the quality of cold-pressed grape seed oils processed in the Republic of Serbia.

\section{MATERIALS AND METHODS}

\subsection{Materials}

Oil samples tested in this work were prepared by the cold pressing of seeds obtained from grapes 
during the process of wine production. The fresh wine pomace from the red (Merlot and Hamburg) and white grape (Italian Riesling and Sila-Serbian autochthonous) varieties was gathered within a few hours after leaving the largest winery on the slopes of the Fruška Gora vineyard in the Republic of Serbia. Then, for a very short time, the pomace was purified using a machine with a rotating, perforated drum, separating the seeds from the grapes' skins. Immediately after that, the seeds were dried in a stream of warm air at about $30{ }^{\circ} \mathrm{C}$ for 24 hours. The content in impurities in cleaned and dried seeds was about $0.2-0.3 \%$ (mostly parts of skins and stunted seeds). Two samples of a blend of different varieties of red, as well as white grape seeds were purchased from small wineries. In this case, wine pomace was collected over a longer period of time; the samples were dried naturally at ambient temperature (at about $20{ }^{\circ} \mathrm{C}$ for several days) and the seeds were separated. All grape cultivars were grown in the same geographical region with similar climatic conditions and soil characteristics, and were harvested at their best maturity. In grape seed samples prepared for pressing, by standard laboratory methods, the contents of moisture (ISO 665:2000) and oil (ISO 659:2009-Soxhlet method) were determined. The obtained results, as well as label information, are presented in Table 1.

\subsection{Production of cold-pressed grape seed oils}

The oil samples were obtained by pressing the cleaned and dried grape seeds with a screw press (Koprulu Machine, Type KYP20D, Turkey), run by a $1.8 \mathrm{~kW}$ electric motor, capacity of $5-7 \mathrm{~kg} / \mathrm{h}$ in a small-size facility for cold-pressed oils. Initially, the press head was heated up to $90^{\circ} \mathrm{C}$. Subsequently, the heaters were switched off and the pressing material was released. The speed of the screw was $25 \mathrm{rpm}$. When the oil started coming out, the speed slowed down to $20 \mathrm{rpm}$. The temperature of the outgoing oil, due to pressure and friction, was about $50-55^{\circ} \mathrm{C}$. After pressing the oil samples were stored for three days at room temperature for natural sedimentation of insoluble impurities to occur, after which they were decanted. Finally, clear oil samples for further analysis were used as average samples from several series of pressing. The samples (each of $1000 \mathrm{~mL}$ ) were kept in a refrigerator at $8 \pm 1{ }^{\circ} \mathrm{C}$ until analysis to avoid oxidation processes (Bjelica et al., 2019).

\subsection{Methods}

Free acidity, given as acid value (AV) (ISO 660:2009), expressed in $\mathrm{mg} \mathrm{KOH/g}$, was determined by volumetric titration of a solution of oil dissolved in ethanol:diethyl ether (1:1) with an ethanolic solution of $0.1 \mathrm{M} \mathrm{KOH}$.

The peroxide value (PV) (ISO 3960:2017), expressed in meqO $/ \mathrm{kg}$, was determined by the reaction of oil (dissolved in acetic acid and isooctane) with a solution of potassium iodide. The liberated iodine was then titrated with a standard volumetric sodium thiosulfate solution.

The $p$-anisidine value ( $p$-AnV) was determined following the ISO standard spectrophotometric method (ISO 6885:2016), measuring the absorbance at $350 \mathrm{~nm}$.

The Totox value was calculated as follows: Totox $=2 \mathrm{PV}+p-\mathrm{AnV}$

The content of total tocopherols and tocotrienols was determined by using the spectrophotometric method according to Paqout et al., (1967). The method is based on the reduction properties of tocophenols/ tocotrienols, which reduce $\mathrm{Fe}^{3+}$ from $\mathrm{FeCl}_{3}$ in the presence of 2-2'dipyridyl and create a red-colored

TABLE 1. Label information, moisture and oil content of investigated grape seed samples

\begin{tabular}{llcc}
\hline Sample codes & Grape varieties & Moisture (\%) & Oil (\% d.m.*) \\
\hline M & Merlot - red grape & $10.12 \pm 0.05$ & $9.87 \pm 0.14$ \\
H & Hamburg - red grape & $8.63 \pm 0.03$ & $11.92 \pm 0.36$ \\
R & Blend of different varieties of red grape & $7.58 \pm 0.06$ & $11.06 \pm 0.28$ \\
IR & Italian Riesling - white grape & $10.02 \pm 0.05$ & $8.89 \pm 0.68$ \\
S & Sila - domestic white grape** & $8.62 \pm 0.04$ & $12.74 \pm 0.40$ \\
W & Blend of different varieties of white grape & $7.98 \pm 0.07$ & $11.28 \pm 0.42$ \\
\hline
\end{tabular}

Values are means \pm standard deviation $(n=3) ; *$ on a dry matter basis; ** Serbian autochthonous grape variety developed at the University of Novi Sad, Faculty of Agriculture, Novi Sad 
complex with $\mathrm{Fe}^{2+}$ ions. The determination was made from unsaponified matter, so the oil saponification and the extraction of unsaponifiable matter was performed, and then a benzene solution of the unsaponified matter developed a colored reaction, where absorbance was measured at $520 \mathrm{~nm}$ wavelength using a spectrophotometer with a blank test.

The determination of tocopherols was carried out using detector RF-535 (Shimadzu, Fluorescence HPLC) coupled to HPLC (Waters M600E, USA) on a reversed-phase Nucleosil 50-5 C18 column (Macherey-Nagel, Germany), using a method based on the procedure described by Carpenter (1979) with some modifications. Operating conditions of the HPLC system were the following: mobile phase: $95 \%$ $\mathrm{CH}_{3} \mathrm{OH}$; flow rate: $1.0 \mathrm{~mL} / \mathrm{min}$.; column temperature: $20{ }^{\circ} \mathrm{C}$; wavelength: $\lambda \mathrm{ex}=295 \mathrm{~nm}, \lambda \mathrm{em}=330 \mathrm{~nm}$. The relative retention time and maximum values of absorption at the given relative retention time were used for the identification of tocopherols in the oil samples. Commercial tocopherol standards were suitably diluted and were used for method validation (solution series from 0.01 to $0.5 \mu \mathrm{g} / \mathrm{mL}$ ), as well as for quantification purposes (solution series from 1.0 to $20.0 \mu \mathrm{g} / \mathrm{mL}$ ).

Vitamin $E$ activity, i.e. vitamin $\mathrm{E}$ equivalent of tocopherols (Mag et al., 2002) was calculated following the formula:

Vitamin $E=\alpha$-toc. $+0.25 \beta+\gamma$-toc. $+0.01 \delta$-toc.

The content in total phenolic compounds was estimated according to the Folin-Ciocalteu colorimetric method (based on the reaction of the reagent with the functional hydroxyl groups of the phenols) as described by Haiyan et al. (2007). The oil was dissolved in hexane and extracted with methanol (three times). The sample was left to stand overnight. After that, the methanolic extract was washed with hexane and an aliquot $(1 \mathrm{~mL})$ was transferred to a volumetric flask $(10 \mathrm{~mL})$, to which the FolinCiocalteu reagent $(0.5 \mathrm{~mL})$ was added. The solution was shaken and left to stand for $3 \mathrm{~min}$. prior to the addition of a saturated solution of sodium carbonate, and dilution with water was made. After 1hour, the absorbance at $725 \mathrm{~nm}$ was measured against a reagent blank using a spectrophotometer. Calibration was performed using gallic acid. The total phenol content was expressed as the equivalent of gallic acid in $\mathrm{mg}$ per kilogram of oil.

Determination of single polyphenols. Phenols from the grape seed oil samples were extracted using a modified procedure by Gouvinhas et al., (2014) and determined on Agilent Technologies 1200 HPLCDAD, coupled with Agilent Technologies 6410A ESI-QqQ-MS/MS, described previously (Bjelica et al., 2019). Approximately $800 \mu \mathrm{L}$ of the sample were transferred to the $4 \mathrm{~mL}$ vial; the mass was accurately measured, and the sample was diluted with $400 \mu \mathrm{L}$ of hexane. The mixture was extracted with $80 \%$ methanol $(600 \mu \mathrm{L})$ with vigorous shaking using the vortex device. After centrifugation (10 minutes at $2500 \mathrm{rpm}$ ), the aqueous methanol layer was transferred to a $2 \mathrm{~mL}$ vessel, and the oil layer was extracted two more times with $80 \%$ methanol. The combined extracts were supplemented with $80 \%$ methanol to $2 \mathrm{~mL}$, filtered through a $0.45 \mu \mathrm{m}$ regenerated cellulose membrane filter and analyzed using LC-DAD-MS/MS. The content of the selected secondary biomolecules was determined by the LCDAD-MS/MS method. A $5 \mu \mathrm{L}$ sample was injected. The separation was performed by the Zorbax Eclipse XDB-C18 column (50 $\mathrm{mm} \times 4.6 \mathrm{~mm}, 1.8 \mu \mathrm{m})$ at 50 ${ }^{\circ} \mathrm{C}$. The components were eluted with a mobile phase based on $0.05 \%$ aqueous solution of formic acid (A) and methanol (B) at a flow rate of $1.0 \mathrm{~mL} / \mathrm{min}$, in gradient mode: 0 min., $30 \% \mathrm{~B}, 6 \mathrm{~min} .70 \% \mathrm{~B}, 9 \mathrm{~min}$. $100 \%$ B, 12 min. 100\% B; re-equilibrium time $3 \mathrm{~min}$. For identification purposes and identity validation, the UV/VIS signal was observed in the range of 190-700 $\mathrm{nm}$. Effluents passed the MS/MS detector without flow sharing. The ion source parameters were: the pressure of the nebulizer $50 \mathrm{psi}$, temperature and flow of drying gas $\left(\mathrm{N}_{2}\right) 350{ }^{\circ} \mathrm{C}$ and $10 \mathrm{~L} / \mathrm{min}$; the voltage on the capillary $4000 \mathrm{~V}$; negative polarity. The compounds were monitored in a dynamic SRM (selected reaction monitoring) mode, with optimized parameters. By sequential dilution of 1:1, a series of commercial standard solutions were prepared in a concentration range of $1.53 \mathrm{ng} / \mathrm{mL}$ to $25.0 \mu \mathrm{g} / \mathrm{mL}$. The concentration of the analyte was determined by the external standard method, using calibration curves in a narrower band-adjusted concentration in the sample. For the quantification, points that directly surrounded the readings in the samples were taken. In most cases, the correlation was not linear but square. For all the compounds, peak areas were determined using Agilent MassHunter Workstation Software Qualitative Analysis (ver. B.03.01). Calibration curves were plotted and sample concentrations calculated by using the OriginLabs Origin Pro (ver. 8.0) software. 
The antiradical capacity of oils in the current study was assessed by the evaluation of the free radical scavenging effect on 2, 2-diphenyl-1picrylhydrazyl radicals (DPPH•), according to the method proposed by Martínez and Maestri (2008). The absorbance was measured on spectrophotometer at $515 \mathrm{~nm}$ using toluene as the blank. Antiradical action toward DPPH radicals was estimated from the difference in absorbance with or without oil sample (control) and the percent of inhibition was calculated from the following formula:

$$
\% \text { Inhibition }=\left[A_{C}-A_{S} / A_{C}\right] \times 100
$$

where: $\mathrm{A}_{\mathrm{C}}=$ absorbance of the control; $\mathrm{A}_{\mathrm{S}}=$ absorbance of the sample.

$\mathrm{EC}_{50}(\mathrm{mgoil} / \mathrm{mgDPPH} \bullet)$ values were expressed as the inhibitory concentration of the oil necessary to decrease the initial DPPH $\bullet$ absorbance by $50 \%$. A lower $\mathrm{EC}_{50}$ value indicates a higher antiradical capacity.

All above-mentioned spectrophotometric measurements were conducted using a UV/VIS spectrophotometer model $\mathrm{T} 80+$ (PG Instruments Limited, London).

\subsection{Chemicals and reagents}

The solvents and chemicals used in these investigations were of analytical grade, except chemicals for the extraction procedure and chromatographic analysis, which were of chromatographic purity. Methanol, ethanol, $\mathrm{KOH}$, pyrogallol and n-hexane were purchased from Merck (Darmstadt, Germany); Folin-Ciocalteu reagent and gallic acid were from Institute Mol Ltd.; formic acid was from J.T. Baker (Deventer, Netherlands), as well as other solvents and reagents. Standards were purchased from Sigma-Aldrich Co. (St. Louis, USA).

\subsection{Statistical analysis}

All results are presented as a mean value \pm standard deviation $(n=3)$. One-way analysis of variance (ANOVA) with a Duncan test was used to determine significant differences among the data at the level of $p<0.05$. Also, two-way ANOVA with the Tukey test was performed at a statistically significant level ( $p$ $<0.05$ ). The degree of linear relationship between two variables was measured using the Pearson's correlation coefficient (r). Statistical analysis was performed using the software SPSS Statistica 20 (IBM Corporation, Armonk, New York, U.S.) and OriginPro 8 (OriginLab Corporation, Northampton, MA 01060 USA).

\section{RESULTS AND DISCUSSION}

\subsection{Chemical characteristics of oils}

Some quality parameters of grape seed oil samples, like AV, PV, $p$-AnV and Totox, are presented in Table 2.

The acid value measures the content in free fatty acids formed by the hydrolytic degradation of oil molecules. Free fatty acids can contribute to the reduction in the shelf-life of oil, so acidity is a very important quality parameter (Prescha et al., 2014). Table 2 shows that all oil samples had low acidity values, below the maximum level $(4 \mathrm{mgKOH} / \mathrm{g})$ allowed by Codex Alimentarius (1999). Similar values have been reported by other authors (Pardo et al., 2009; Boso et al., 2018). The lowest acid value was found in the oil of the red grape Merlot variety $(0.62 \pm 0.03 \mathrm{mgKOH} / \mathrm{g})$, as well as in the oil of the Serbian autochthonous white grape Sila variety

TABLE 2. Some chemical quality parameters of red and white cold-pressed grape seed oils

\begin{tabular}{|c|c|c|c|c|}
\hline & $\mathrm{AV}(\mathrm{mgKOH} / \mathrm{g})$ & $\mathrm{PV}\left(\mathrm{meqO}_{2} / \mathrm{kg}\right)$ & $p$-AnV & Totox \\
\hline \multicolumn{5}{|c|}{ Cold-pressed oil of red grape seed } \\
\hline Merlot & $0.62 \pm 0.03^{\mathrm{a}}$ & $2.48 \pm 0.04^{\mathrm{b}}$ & $0.64 \pm 0.03^{\mathrm{a}}$ & $5.60 \pm 0.08^{\mathrm{a}}$ \\
\hline Hamburg & $0.94 \pm 0.04^{\mathrm{b}}$ & $1.90 \pm 0.04^{\mathrm{a}}$ & $0.56 \pm 0.03^{\mathrm{a}}$ & $4.36 \pm 0.09^{\mathrm{a}}$ \\
\hline R- blend seeds & $1.61 \pm 0.05^{\mathrm{c}}$ & $8.14 \pm 0.07^{\mathrm{e}}$ & $1.78 \pm 0.05^{\mathrm{b}}$ & $18.04 \pm 0.53^{\mathrm{c}}$ \\
\hline \multicolumn{5}{|c|}{ Cold-pressed oil of white grape seed } \\
\hline It. Riesling & $0.73 \pm 0.03^{\mathrm{ab}}$ & $5.08 \pm 0.21^{\mathrm{c}}$ & $2.14 \pm 0.06^{\mathrm{d}}$ & $12.30 \pm 0.38^{\mathrm{b}}$ \\
\hline Sila & $0.66 \pm 0.03^{\mathrm{a}}$ & $6.84 \pm 0.07^{\mathrm{d}}$ & $1.83 \pm 0.05^{b}$ & $15.51 \pm 0.17^{\circ}$ \\
\hline W-blend seeds & $2.42 \pm 0.28^{\mathrm{d}}$ & $10.08 \pm 0.18^{\mathrm{f}}$ & $1.94 \pm 0.04^{\mathrm{c}}$ & $22.10 \pm 0.38^{\circ}$ \\
\hline
\end{tabular}

$\mathbf{A V}$ - acid value; $\mathbf{P V}$ - peroxide value; $p$-AnV - para-Anisidine value; Totox value $=2 \mathrm{PV}+p$-AnV: Values are means \pm standard deviation $(n=3)$; Different letters in the same column indicate significantly different values $(p<0.05$, one-way ANOVA with Duncan test) 
$(0.66 \pm 0.03 \mathrm{mgKOH} / \mathrm{g})$. The acidity of the oils was slightly higher in the two other grape varieties (Hamburg - $0.94 \pm 0.04$ and Ital. Riesling - $0.73 \pm$ $0.03 \mathrm{mgKOH} / \mathrm{g}$ ); however, the oils extracted from a blend of different red $(\mathrm{R})$ and white $(\mathrm{W})$ grape varieties had increased acidity, $1.61 \pm 0.05$ and $2.42 \pm$ $0.28 \mathrm{mgKOH} / \mathrm{g}$, respectively. An explanation for the low acid values can be the fact that grape cultivars were harvested at their highest level of maturity. Namely, Rubio et al., (2009) revealed that the oil from the grape seeds collected at an early stage of growth had a considerably higher free acidity value compared to the oil extracted from grapes collected at later stages of maturity. Furthermore, the pomace from a large winery company was dried quickly, in contrast to collecting and drying pomace from small wineries. Careful and fast drying of the pomace after production of wine is required to achieve high valuable grape seed oils. Otherwise, the quality of the resulting oil is affected by various microorganisms which enhance acidity (Matthäus, 2008).

PV defines the contents in lipid hydroperoxides in oils formed during auto- and photo-oxidation processes. All investigated oil samples were characterized by such values for PV that did not exceed the limit for cold-pressed oils of $15 \mathrm{meqO}_{2} /$ $\mathrm{kg}$, recommended by Codex standards for vegetable oils (Codex, 1999). The PV for the oil from red grape seeds were lower and ranged from $1.90 \pm 0.04$ (Hamburg) to $8.14 \pm 0.07 \mathrm{meqO}_{2} / \mathrm{kg}$ (R-blend), in contrast to the oil from white grape seeds with a level of $5.08 \pm 0.21$ (Ital. Riesling) to $10.08 \pm 0.18 \mathrm{meqO}_{2} /$ $\mathrm{kg}$ (W-blend). Regarding the PV, it can be concluded that there were statistically significant differences among all the oil samples at $p<0.05$.

The data published for the PV of grape seed oil commercially available in the UK was $1.0 \pm 0.0$ $\mathrm{meqO}_{2} / \mathrm{kg}$ (Madawala et al., 2012). In pressed oil obtained from different red grape varieties grown in Spain, Pardo et al., (2009) found PV values from $5.99 \mathrm{meqO}_{2} / \mathrm{kg}$ (hot air drying of seed, at $50{ }^{\circ} \mathrm{C}$ for 6h) to $13.50 \mathrm{meqO}_{2} / \mathrm{kg}$ (ambient temperature dried seeds, at $20^{\circ} \mathrm{C}$ for 7 days). In oils obtained from cold extraction of bagasse-derived seeds from the white grape varieties, PV values were in the range of 11 \pm 1.69 to $26 \pm 2.89 \mathrm{meqO}_{2} / \mathrm{kg}$ (Boso et al., 2018). Kiralan et al., (2019) concluded that the PV values for fresh cold-pressed oils were 1.82, 12.2 and 26.5 $\mathrm{meqO}_{2} / \mathrm{kg}$ for flaxseed, grape seed and black cumin seed oils, respectively. The PV value of commercial cold-pressed grape seed oil from the European market by Radočaj and Dimić (2013) was $5.07 \pm$ $0.05 \mathrm{meqO}_{2} / \mathrm{kg}$.

The $p$-AnV reflects the contents in secondary lipid oxidation products (saturated and unsaturated carbonyl compounds), resulting from the decomposition of hydroperoxides, so $p$-AnV along with $\mathrm{PV}$, indicate the progression of rancidity in the oils. The $p-\mathrm{AnV}$ in all the analyzed oil samples (Table 2) were in the range of $0.56 \pm 0.03$ to $2.14 \pm$ 0.06 ; whereby the lowest $p-\mathrm{AnV}$ was found in the oil of the red grape Hamburg variety. Generally, all three red grape seed oils had somewhat lower $p$-AnV in relation to oils from white grape seeds. The $p-\mathrm{AnV}$ of the oils had the following values: Merlot $(0.64 \pm$ $0.03)$ and Hamburg $(0.56 \pm 0.03)$ (without significant differences between these two samples, $p<0.05)$, $<$ R-blend $(1.78 \pm 0.05)$ and Sila $(1.83 \pm 0.05)$ (without significant differences, $p<0.05),<\mathrm{W}$-blend $(1.94 \pm$ $0.04)$ and $<$ Ital. Riesling $(2.14 \pm 0.06)$.

The food safety of these oils, with respect to the $p$-AnV value, is difficult to evaluate because of the lack of an established limit value for this parameter in cold-pressed oils (recommended $p$-AnV value for fresh fully refined oil is $<10$ ). However, cold-pressed seed oils, as a rule, have very low $p$-AnV, indicating low levels of carbonyl compounds because of the absence of heat during the oil extraction process. The mean values of $p-\mathrm{AnV}$ in a number of fresh coldpressed oils from the seeds and fruits of different plants (other than grape seed oil) found in the Polish market (Prescha et al., 2014) were in the range of $0.25 \pm 0.05$ to $8.60 \pm 3.20$. According to their results, the lowest $p$-AnV was found for sesame oil (0.20.3 ), but the largest variability occured in rose hip oil (4.22-11.88) and pumpkin seed oil (1.48-8.17).

The total secondary oxidation products, i.e. Totox, in our samples, measured as a sum of PV and $p$-AnV, ranged from $2.45 \pm 0.09$ to $12.03 \pm 0.38$. The Totox value for oils from the red grape Merlot and Hamburg varieties were the smallest; whereas they were 2 to 3 times larger in the oils of white grape Ital. Riesling and Sila varieties. The largest Totox values of $10.24 \pm 0.53(\mathrm{R})$ and $12.03 \pm 0.38(\mathrm{~W})$ were found in the oils from blended seeds, which may be a reflection of pomace collection and the drying process. In the reviewed literature, data on the Totox values for grape seed oil were very limited. 
In grape seed oil, as a specialty oil from a local retail store in Reading (UK), the Totox value was $17.5 \pm$ 0.1 (Madawala et al., 2012), but there was a lack of accurate background information on the sample.

\subsection{Nutritive value of oils}

As cold pressing does not involve chemicals or heat treatment during the oil production process, it implies that cold-pressed seed oils may contain phytochemicals, as well as natural antioxidants, more than refined oils. Some results from our previous work about total tocopherol and phenol contents and their fractionation (Bjelica et al., 2019) have been included to support this new investigation.

\subsubsection{Tocopherol profile and vitamin E activity}

The profile of tocopherols in the investigated grape seed oils is characterized by the presence mainly of the $\alpha$-tocopherol (Table 3), where the amount ranged from $29.5 \pm 1.09$ to $65.5 \pm 1.63$ $\mathrm{mg} / \mathrm{kg}$. Other forms of tocopherols were found at considerably lower concentrations, at most up to $7.6 \pm 0.2 \mathrm{mg} / \mathrm{kg}$ for $\beta+\gamma$-tocopherols and up to 3.9 $\pm 0.1 \mathrm{mg} / \mathrm{kg}$ for $\delta$-tocopherols. All the results were significantly different at $p<0.05$. Vitamin $\mathrm{E}$ is of particular importance for the nutritive value of the oil because of its excellent antioxidant properties (Crews et al, 2006). The biologically important vitamin $\mathrm{E}$ activity (expressed as $\alpha$-tocopherol equivalent) of the samples is somewhat higher and ranges from 30.0 to $66.9 \mathrm{mg} / \mathrm{kg}$, since the share of $\alpha$-tocopherol is the highest in all samples and ranged from about
85 to $92 \%$. It can be concluded that the vitamin $\mathrm{E}$ activity of white grape seed oil is significantly higher compared to red grape seed oil. The highest vitamin E activity was determined in the oil of a blend of different unknown white grape seed varieties, 66.9 $\mathrm{mg} / \mathrm{kg}$, as well as in the oil of Ital. Riesling white grape seeds, $65.9 \mathrm{mg} / \mathrm{kg}$.

By analyzing the results of the vitamin E activity in Table 3 according to the Canadian Food Inspection Agency (1996), it can be said that only white grape seed oils could be labelled as a "Source of vitamin E", since they contain vitamin $\mathrm{E}$ in the amount of at least $0.5 \mathrm{mg}$ per 10 $\mathrm{g}$ of oil (table portion), i.e. they provide between 5 and $15 \%$ of the recommended daily intake. From this aspect, white grape seed oil can be compared to peanut oil, palm and soybean oil, unlike corn and rapeseed oil that represent "A good source of vitamin E." Sunflower and cotton oils could be claimed as "An outstanding source of vitamin E" (Mag et al., 2002). The relevant literature data on the contents in tocopherol and tocotrienol in seed oils are very different. The biologically active vitamin $\mathrm{E}$ content relative to that of $\alpha$-tocopherol ranged from 0.5 to $118 \mathrm{mg} / \mathrm{kg}$ of oil for the tanninremoved grape seed sample and the commercial grape seed oil, respectively (Oomah et al., 1998). Crews et al., (2006) quoted data for $\alpha$-tocopherol in grape seed oil (extracted with hexane) from less than $10 \mathrm{mg} / \mathrm{kg}$ up to $229 \mathrm{mg} / \mathrm{kg}$, indicating significant variations depending on the variety of the grape and the production area (France, Italy, Spain). Also, according to their results, the major

TABLE 3. Tocopherol content and vitamin E activity of cold-pressed red and white grape seed oils

\begin{tabular}{lcccccc}
\hline \multirow{2}{*}{ Tocopherols (mg/kg) } & \multicolumn{3}{c}{ Red grapes } & \multicolumn{3}{c}{ White grapes } \\
\cline { 2 - 7 } & Merlot & Hamburg & R-blend & Ital. Riesling & Sila & W-blend \\
\hline$\alpha-$ & $38.4 \pm 1.2^{\mathrm{b}}$ & $39.8 \pm 1.5^{\mathrm{b}}$ & $29.5 \pm 1.1^{\mathrm{a}}$ & $64.0^{\mathrm{a}} \pm 1.9^{\mathrm{d}}$ & $49.6 \pm 1.4^{\mathrm{c}}$ & $65.5 \pm 1.6^{\mathrm{d}}$ \\
$\beta+\gamma-$ & $3.0 \pm 0.1^{\mathrm{b}}$ & $5.2 \pm 0.2^{\mathrm{d}}$ & $2.0 \pm 0.1^{\mathrm{a}}$ & $7.6 \pm 0.2^{\mathrm{f}}$ & $4.6 \pm 0.1^{\mathrm{c}}$ & $5.5 \pm 0.2^{\mathrm{e}}$ \\
$\delta-$ & $1.2 \pm 0.0^{\mathrm{b}}$ & $1.8 \pm 0.0^{\mathrm{c}}$ & $0.8 \pm 0.0^{\mathrm{a}}$ & $2.8 \pm 0.1^{\mathrm{d}}$ & $3.9 \pm 0.1^{\mathrm{f}}$ & $3.5 \pm 0.4^{\mathrm{e}}$ \\
Vitamin E activity* & $39.1^{\mathrm{b}}$ & $41.1^{\mathrm{c}}$ & $30.0^{\mathrm{a}}$ & $65.9^{\mathrm{e}}$ & $49.8^{\mathrm{d}}$ & $66.9^{\mathrm{f}}$ \\
Share of $\alpha$-toc. $(\%)$ & $90.1^{\mathrm{e}}$ & $85.0^{\mathrm{b}}$ & $91.3^{\mathrm{f}}$ & $86.0^{\mathrm{c}}$ & $84.8^{\mathrm{a}}$ & $87.9^{\mathrm{d}}$ \\
Total tocopherols & $42.6 \pm 0.6$ & $46.8 \pm 0.8$ & $32.3 \pm 0.6$ & $74.8 \pm 1.0$ & $58.1 \pm 0.8$ & $74.5 \pm 0.7$ \\
\hline
\end{tabular}

Values are means \pm standard deviation $(n=3)$; *expressed as $\alpha$-tocopherol equivalent $(\mathrm{mg} / \mathrm{kg})$;

Different letters in the same row indicate significantly different values $(p<0.05$, one-way ANOVA with Duncan test) 
tocopherol was the $\alpha$-form. Other tocopherol forms were found as follows: $\beta$-tocopherol $<10$ to $133 \mathrm{mg} / \mathrm{kg}, \gamma$-tocopherol $<10$ to $169 \mathrm{mg} / \mathrm{kg}$ and $\delta$-tocopherol $<10$ to $69 \mathrm{mg} / \mathrm{kg}$. The contents in $\alpha$-tocopherol in cold-pressed seed oils of seven local grape cultivars from the south-eastern part of Turkey were much higher than in our investigation and ranged from 77.33 to $225.40 \mathrm{mg} / \mathrm{kg}$. However, $\beta$ - and $\delta$-tocopherol were not detected in any of the oils (Demirtas et al., 2013). In the cold-pressed grape seed oil of the Merlot variety, Oomah et al., (1998) determined a vitamin E content of $10.6 \mathrm{mg} /$ $\mathrm{kg}$; whereas in the seed oil of the same variety grown in China, When et al., (2016) determined a vitamin $\mathrm{E}$ ( $\alpha$-tocopherol) content of $90.00 \pm 1.28$ $\mathrm{mg} / \mathrm{kg}$ (the seeds were subjected to supercritical carbon dioxide extraction). Fernandes et al., (2013) published that the seed oils of ten Portuguese grape varieties were also a very good source of vitamin E (148 to $358 \alpha$-tocopherol equivalents-including tocotrienol forms). The tocopherol profile of coldpressed grape seed oil from a local cold pressing company in Turkey was as follows: $123.0 \pm 1.76$ $\mathrm{mg} / \mathrm{kg}, 16.7 \pm 0.01 \mathrm{mg} / \mathrm{kg}$ and $0.56 \pm 0.01 \mathrm{mg} / \mathrm{kg}$ for $\alpha$-, $\gamma$ - and $\delta$-tocopherol, respectively (Kiralan et al., 2019).

\subsubsection{Profile of phenolic compounds}

Belonging to the group of very important biomolecules, the phenolic fraction of vegetable oil contributes not only to its sensory taste, but also to the nutritive quality and shelf-life of the edible oils which exhibit strong antioxidant activity. Matthäus (2008) stated that grape seeds contain significant amounts of various phenolic compounds. However, due to their limited solubility, only small amounts pass into the oil. The composition of the phenolic compounds in our investigated cold-pressed oil samples is presented in Table 4 .

As shown in Table 4, the most significant fraction of phenolic compounds in all the oil samples was ursolic acid, and the highest content was found in the oil of red grape varieties. The statistical analysis of the ursolic acid content showed significant differences $(p<0.05)$ among all samples and had the following order: Hamburg $(336.3 \pm 4.8 \mu \mathrm{g} / \mathrm{g})>$ R-blend $(305 \pm 11 \mu \mathrm{g} / \mathrm{g})>\mathrm{S}(212 \pm 17 \mu \mathrm{g} / \mathrm{g})>$ Ital. Riesling $(159 \pm 32 \mu \mathrm{g} / \mathrm{g})>\operatorname{Merlot}(82.3 \pm 12.5 \mu \mathrm{g} / \mathrm{g})$ and $>$ W-blend $(47.1 \pm 6.3 \mu \mathrm{g} / \mathrm{g})$. The presence of ursolic acid in all the oil samples might be due to the fact that the grape cultivars analyzed in this study originated from the same geographical region and

TABLE 4. Phenolic composition in cold-pressed red and white grape seed oils

\begin{tabular}{lcccccc}
\hline Phenols $(\mu \mathrm{g} / \mathbf{g})$ & \multicolumn{3}{c}{ Red grapes } & \multicolumn{2}{c}{ White grapes } \\
\cline { 2 - 7 } & Merlot & Hamburg & R-blend & Ital. Riesling & Sila & W-blend \\
\hline$p$-OH benzoic acid & $<0.08$ & $<0.08$ & $<0.08$ & $<0.09$ & $<0.09$ & $0.495 \pm 0.031$ \\
$p$-coumaric acid & $<0.08$ & $0.398 \pm 0.030^{\mathrm{b}}$ & $0.475 \pm 0.006^{\mathrm{c}}$ & $<0.09$ & $0.126 \pm 0.007^{\mathrm{a}}$ & $0.146 \pm 0.026^{\mathrm{a}}$ \\
Vanillic acid & $<0.3$ & $0.878 \pm 0.116^{\mathrm{b}}$ & $1.70 \pm 0.04^{\mathrm{c}}$ & $<0.3$ & $<0.3$ & $0.50 \pm 0.11^{\mathrm{a}}$ \\
Ferulic acid & $<0.08$ & $0.226 \pm 0.012^{\mathrm{c}}$ & $0.191 \pm 0.024^{\mathrm{b}}$ & $<0.09$ & $<0.09$ & $0.090 \pm 0.001^{\mathrm{a}}$ \\
Resveratrol & $<0.3$ & $5.16 \pm 0.08^{\mathrm{b}}$ & $3.99 \pm 0.21^{\mathrm{a}}$ & $<0.3$ & $<0.3$ & $<0.3$ \\
Morin & $<0.3$ & $0.979 \pm 0.011^{\mathrm{c}}$ & $0.842 \pm 0.109^{\mathrm{b}}$ & $<0.3$ & $<0.3$ & $0.19 \pm 0.02^{\mathrm{a}}$ \\
Naringenin & $0.008 \pm 0.001^{\mathrm{a}}$ & $0.239 \pm 0.009^{\mathrm{d}}$ & $1.189 \pm 0.009^{\mathrm{c}}$ & $0.015 \pm 0.003^{\mathrm{a}}$ & $0.032 \pm 0.003^{\mathrm{b}}$ & $0.068 \pm 0.004^{\mathrm{c}}$ \\
Ursolic acid & $82.3 \pm 12.5^{\mathrm{b}}$ & $336.3 \pm 4.8^{\mathrm{f}}$ & $305 \pm 11^{\mathrm{e}}$ & $159 \pm 32^{\mathrm{c}}$ & $212 \pm 17^{\mathrm{d}}$ & $47.1 \pm 6.3^{\mathrm{a}}$ \\
Proto-catechinic & $<0.04$ & $0.173 \pm 0.011^{\mathrm{b}}$ & $0.349 \pm 0.012^{\mathrm{c}}$ & $<0.04$ & $<0.04$ & $0.059 \pm 0.011^{\mathrm{a}}$ \\
acid & $0.023 \pm 0.003^{\mathrm{b}}$ & $0.216 \pm 0.004^{\mathrm{c}}$ & $0.314 \pm 0.005^{\mathrm{d}}$ & $0.010 \pm 0.001^{\mathrm{a}}$ & $0.015 \pm 0.001^{\mathrm{a}}$ & $0.011 \pm 0.001^{\mathrm{a}}$ \\
Krizoeriol & $0.216 \pm 0.133^{\mathrm{b}}$ & $0.399 \pm 0.068^{\mathrm{c}}$ & $0.555 \pm 0.018^{\mathrm{d}}$ & $0.016 \pm 0.001^{\mathrm{a}}$ & $<0.009$ & $<0.009$ \\
Amentoflavon & $<0.3$ & $5.80 \pm 0.16^{\mathrm{c}}$ & $4.68 \pm 0.21^{\mathrm{b}}$ & $<0.3$ & $<0.3$ & $1.18 \pm 0.36^{\mathrm{a}}$ \\
Kaempherol & & &
\end{tabular}

Values are means \pm standard deviation $(n=3)$; Different letters in the same row indicate significantly different values $(p<0.05$, one-way Anova with Duncan test) 
growing conditions. Namely, Cicero et al., (2018) suggested that the polyphenol profile of grape seed oil may be affected by the variety of grape seeds and environmental growing conditions, rather than extraction procedures. The interest in ursolic acid is related to its beneficial effects on human health due to antioxidant, antimicrobial, anti-inflammatory, hepatoprotective, immunomodulatory, anti-tumor, cardioprotective, and antihyperlipidemic activities, among others (López-Hortas et al., 2018). When considering other phenolic fractions in a significant amount (Table 4$)$, it was resveratrol $(<0.3$ to 5.16 $\pm 0.08 \mu \mathrm{g} / \mathrm{g})$ and kaempherol $(<0.3$ to $5.80 \pm 0.16$ $\mu \mathrm{g} / \mathrm{g})$, but they were far less compared to ursolic acid. By applying two-way ANOVA on the obtained results of these phenolic fractions, as well as the results of the Tukey test, it can be concluded that all oil samples were statistically significant. Among the investigated samples, on average, red grape seed oils had higher contents in phenolic compounds, except for $\mathrm{p}-\mathrm{OH}$ benzoic acid, with respect to the white grape seed oils. Oil from the red grape Hamburg variety was the richest in all phenolic fractions, about $336.3 \pm 4.8 \mu \mathrm{g} / \mathrm{g}$.

Bail et al., (2008) determined the total phenolic components of 9 samples of cold-pressed seed oils of different grape varieties and published the contents to be ranging from $59.0 \pm 0.02$ to 115.5 $\pm 0.01 \mu \mathrm{g} / \mathrm{g}$. Lower values were found for refined oils, as well as for seed oil which was heated at 60 ${ }^{\circ} \mathrm{C}$ for $30 \mathrm{~min}$. before pressing. The same authors also found lower contents in phenolic ingredients in white grape seed oil. Recently, Cicero et al., (2018) published that cold-pressed grape seed oil from the Brazilian region, Minas Gerais, had the lowest contents in polyphenols. The phenolic profile of the investigated oils from these authors was dominated by the flavonoids apigenin 7 -glucoside $(0.74 \mu \mathrm{g} / \mathrm{g})$, and luteolin $(0.63 \mu \mathrm{g} / \mathrm{g})$; whereas phenolic acids, such as $p$-coumaric $(0.19 \mu \mathrm{g} / \mathrm{g})$, and caffeic $(0.27$ $\mu \mathrm{g} / \mathrm{g})$ acids, were detected in lower amounts. An exception was presented by gallic acid, which was found in the amount of $2.97 \mu \mathrm{g} / \mathrm{g}$. Kiralan et al., (2019) determined 8 bioactive and phenolic compounds including vanillin $(0.33 \mu \mathrm{g} / \mathrm{g})$, vanillic acid $(0.39 \mu \mathrm{g} / \mathrm{g}), \quad p$-coumaric acid $(0.08 \mu \mathrm{g} / \mathrm{g})$, dihydroquercetin $(2.49 \mu \mathrm{g} / \mathrm{g})$, luteolin $(0.67 \mu \mathrm{g} / \mathrm{g})$, campherol $(0.34 \mu \mathrm{g} / \mathrm{g})$, apigenin $(0.01 \mu \mathrm{g} / \mathrm{g})$ and acacetin $(0.31 \mu \mathrm{g} / \mathrm{g})$ in cold-pressed grape seed oil.

\subsubsection{Total contents in biomolecules and $\mathrm{EC}_{50}$ values}

Total contents in biomolecules, like tocopherols and tocotrienols and phenolic compounds, as well as antiradical capacity, assessed by the evaluation of the free radical scavenging effect of oils, are presented in Table 5.

Comparing the results of the total tocopherol and tocotrienol contents (Table 5) with the results of total tocopherol contents (Table 3), it can be concluded that the investigated grape seed oils showed a significantly higher content in tocotrienols than tocopherols. This is also evidenced by the literature data. The major compound found in grape seed oil is $\gamma$-tocotrienol (Crews et al., 2006; Fernandes et al., 2013). The contents in all tocols in our tested samples ranged from at least $338.14 \pm 3.35 \mathrm{mg} / \mathrm{kg}$ (blend of different red grape varieties) up to 575.23 $\pm 4.46 \mathrm{mg} / \mathrm{kg}$ (Merlot variety). Although all samples

TABLE 5. Total tocol and total phenol contents and $\mathrm{EC}_{50}$ values for cold-pressed red and white grape seed oils

\begin{tabular}{|c|c|c|c|}
\hline & Total tocols* (mg/kg) & Total phenols (mgGAE/kg) & $\mathbf{E C}_{50} * *$ \\
\hline \multicolumn{4}{|c|}{ Cold-pressed oil of red grape seed } \\
\hline Merlot & $575.23 \pm 4.46^{\mathrm{f}}$ & $12.66 \pm 1.07^{\mathrm{b}}$ & $65.34 \pm 0.32^{\mathrm{c}}$ \\
\hline Hamburg & $338.14 \pm 3.35^{\mathrm{a}}$ & $44.69 \pm 1.56^{\mathrm{c}}$ & $32.66 \pm 0.43^{b}$ \\
\hline R-blend & $373.55 \pm 2.88^{b}$ & $54.92 \pm 0.93^{\mathrm{d}}$ & $29.84 \pm 1.07^{\mathrm{a}}$ \\
\hline \multicolumn{4}{|c|}{ Cold-pressed oil of white grape seed } \\
\hline Ital. Riesling & $463.99 \pm 2.57^{\mathrm{e}}$ & $9.29 \pm 0.84^{\mathrm{a}}$ & $95.63 \pm 1.48^{\mathrm{f}}$ \\
\hline Sila & $438.77 \pm 5.37^{\mathrm{c}}$ & $11.94 \pm 1.72^{\mathrm{b}}$ & $89.45 \pm 1.03^{\mathrm{d}}$ \\
\hline W-blend & $452.41 \pm 0.89^{d}$ & $8.27 \pm 0.53^{\mathrm{a}}$ & $92.50 \pm 1.17^{\mathrm{e}}$ \\
\hline
\end{tabular}

*Content in total tocopherols and tocotrienols; **(mg oil/mg DPPH radicals needed to decrease the initial DPPH $\bullet$ concentration by $50 \%)$; Values are means \pm standard deviation $(n=3)$; Different letters in the same row indicate significantly different values $(p<0.05$, one-way ANOVA with Duncan test) 
were significantly different, it can be said that the total contents in tocols in oils from white grape seeds were relatively homogeneous, from $438.77 \pm 5.37$ to $463.99 \pm 2.57 \mathrm{mg} / \mathrm{kg}$. According to the literature data (Baydar and Akkurt, 2001) in the seed oils from the grape cultivar Hamburg and Riesling from the vineyard of Ankara (Turkey), the concentration of total tocopherols was $401 \pm 11.04$ and $364 \pm 14.25$ $\mathrm{mg} / \mathrm{kg}$, respectively. The same authors found that, generally, the tocopherol concentration in red grape seed oil was higher $(357 \pm 9.96$ to $578 \pm 27.65 \mathrm{mg} /$ $\mathrm{kg})$ in comparison with white grape seed oil $(364 \pm$ 14.25 to $486 \pm 23.66 \mathrm{mg} / \mathrm{kg}$ ). The total tocopherol and tocotrienol contents in new monovarietal coldpressed grape seed oils derived from white grape varieties collected in North-western Spain ranged between $360 \pm 2.61$ and $445.5 \pm 36.5 \mathrm{mg} / \mathrm{kg}$ (Boso et al., 2018). Demirtas et al., (2013) observed variation in total tocol contents $(394-755 \mathrm{mg} / \mathrm{kg}$ ) in cold-pressed oil from grape cultivars originating from the same geographical region in the southeastern part of Turkey with similar climatic and soil characteristics. Our results are in accordance with the cited literature data.

Regarding the total phenol contents, it can be said that depending on the variety, it was on average higher in the cold-pressed oils obtained from red grape varieties $(12.66 \pm 1.07$ to $54.92 \pm 0.93 \mathrm{mgGAE} /$ $\mathrm{kg})$ compared to white grape varieties $(8.27 \pm 0.53$ to $11.94 \pm 1.72 \mathrm{mgGAE} / \mathrm{kg}$ ). Demirtas et al., (2013) reported that the total phenol contents in seven different grape seed oils ranged from $21.9 \pm 0.14$ to $47.0 \pm 0.30 \mathrm{mgGAE} / \mathrm{kg}$ oil and these values are similar to our results. Bail et al., (2008) measured the total phenol contents in virgin cold-pressed unfiltered grape seed oils and the contents ranged from $59 \pm$ 0.02 to $115.5 \pm 0.01 \mathrm{mgGAE} / \mathrm{kg}$ of oil. According to Lutterodt et al., (2011) the total phenolic content was much higher when using a Soxhlet extraction method for grape seed oil (ethanol, 3h) and it ranged from $160 \pm 0.00$ to $800 \pm 0.01 \mathrm{mg} \mathrm{GAE} / \mathrm{kg}$ of oil. Wen et al., (2016) reported the contents in total phenolics of $98.19 \pm 0.02 \mathrm{mgGAE} / \mathrm{kg}$ for the red grape Cabernet Sauvignon variety, while Chardonnay (white grape variety) represented total phenolic contents of 46.6 $\pm 3.24 \mathrm{mgGAE} / \mathrm{kg}$. The authors concluded that this may be due to the presence of anthocyanins with the main phenolics, which appeared to be red in color. Recently, Kiralan et al., (2019) published that many more total phenolic compounds, 924.2 $\pm 20.41 \mathrm{mgGAE} / \mathrm{kg}$, were present in grape seed oil obtained from a local cold-pressing company (Istanbul, Turkey). The amounts of phenolics in grape seeds may vary greatly according to location, climate, cultivar, vintage, post-harvest treatment and storage conditions. On the other hand, low molecular weight phenolics have low solubility in oil and some phenolic acids can be bound to the seed material, so the total phenolic content in oil may also vary (Lutterodt et al., 2011).

The $\mathrm{EC}_{50}$ values were calculated as the inhibitory concentration of the oil necessary to decrease initial DPPH radical absorbance by $50 \%$, whereby a lower $\mathrm{EC}_{50}$ value indicates a higher antiradical capacity. The $\mathrm{EC}_{50}$ value of grape seed oils in this study ranged from $29.84 \pm 1.07$ to $95.63 \pm 1.48 \mathrm{mg}$ oil/ mg DPPH (Table 5). Consequently, the highest $\mathrm{EC}_{50}$ was registered for the white grape seed oil of the Ital. Riesling variety; while the lowest $\mathrm{EC}_{50}$ was found for the oil of unknown varieties of red grapes, R-blend ( $p$ $<0.05)$. In accordance with this, the oil from the red grape seed blend had the highest antiradical power followed by the Hamburg and Merlot varieties; while the lowest antiradical potential was found for grape seed oil It. Riesling $(p<0.05)$. This can be explained by the fact that the red grape oils have far higher contents in total phenolic compounds compared to white grape oils.

It is worth mentioning that a strong negative relationship between $\mathrm{EC}_{50}$ and content in total phenols was observed, where (r) was $-943(p=$ 0.01). However, Wen et al., (2016) indicated that the antioxidant activities of grape seed oil are not just the function of phenolics, but might be a combined effect of phenolics, vitamin $\mathrm{E}$ and sterols. Furthermore, a positive relationship between $\mathrm{EC}_{50}$ and total tocopherol/tocotrienol content was determined ( $\mathrm{r}$ value was 0.543 at $p=0.05$ ). On the other hand, the content in total tocols showed a negative moderate correlation with the content in total phenols, where (r) was $-0.732(p=0.01)$.

Two-way ANOVA and the Tukey test were performed at a significance level of $p<0.05$, even though factorial analysis was not the focus of this paper. The relevant factors were grape color (red or white) and the origin of the seeds (variety or blend of different varieties). The Tukey test showed that there was no statistically significant difference in total 
tocol contents in cold-pressed oils obtained from red or white grape varieties or a blend of different red and white seed varieties.

The opposite effect was found for total phenols. There was a statistically significant difference between the total phenol contents in cold-pressed oils obtained from red or white grape varieties and the total phenol contents in the cold-pressed oils obtained from the seed of the grape varieties or a blend of different varieties.

By applying two-way ANOVA on the obtained results for $\mathrm{EC}_{50}$, as well as the analysis of the Tukey test $(p<0.05)$, we can identify a statistically significant difference in $\mathrm{EC}_{50}$ in cold-pressed oils obtained from red or white grape varieties, but there was no statistically significant difference in the $\mathrm{EC}_{50}$ in cold-pressed oils obtained from the seeds of the grape varieties, or a blend of different varieties.

\section{CONCLUSIONS}

The results of the investigation of cold-pressed oil samples obtained from grapes grown in the Fruška Gora vineyard in the Republic of Serbia showed good oil quality, but pronounced seed oil nutritive profile differences for red and white grape varieties were observed. The highest content, 575.23 $\pm 4.46 \mathrm{mg} / \mathrm{kg}$, of total tocols was found in the red grape seed oil of the Merlot variety. Red grape seed oils also indicated better DPPH radical scavenging capacity, but the vitamin E activity of 49.8 to 66.9 $\mathrm{mg} / \mathrm{kg}$ was significantly higher in white grape seed oils. The most prevalent phenolic fraction in all oil samples was ursolic acid, at up to $336.3 \pm 4.8 \mu \mathrm{g} / \mathrm{g}$ in the grape seed oil from the Hamburg variety.

All the presented quality characteristics of cold-pressed grape seed oils are highly valued and encourage production this kind of oil in larger quantities. However, the chemical quality of oil highly depends on the period of time needed for seed extraction from the pomace, in terms of avoiding hydrolytic and oxidative degradation. According to our results, a longer period of time indicated higher acid, peroxide and Totox values ( 2 to 4 times more) in oils from blends of different grape seed varieties obtained from pomace collected from small wineries. Overall, the results could be used for the insights of some chemical parameters and the most important bioactive components responsible for the quality of cold-pressed grape seed oil from this region.

\section{REFERENCES}

Bail S, Stuebiger G, KristS, Unterweger H, Buchbauer G. 2008. Characterisation of various grape seed oils by volatile compounds, triacylglycerol composition, total phenols and antioxidant capacity. Food Chem. 108, 1122-1132. https:// doi.org/10.1016/j.foodchem.2007.11.063

Baydar NG, Akkurt M. 2001. Oil content and oil quality properties of some grape seeds. Turk. $J$. Agric. For. 25, 163-168.

Bjelica M, Vujasinović V, Rabrenović B, Dimić S. 2019. Some chemical characteristics and oxidative stability of cold-pressed grape seed oils obtained from different winery waste. Eur. J. Lipid Sci. Technol. 121, 1-10. https://doi. org/10.1002/ejlt.201800416

Boso S, Gago P, Santiago JL, Rodriguez-Canas E, Martinez MC. 2018. New monovarietal grape seed oils derived from white grape bagasse generated on an industrial scale at a winemaking plant. LWT-Food Sci. Technol. 92, 388-394. https://doi.org/10.1016/j.lwt.2018.02.055

Canadian Food Inspection Agency. 1996. Guide to Food Labeling and Advertising, Nutrient Claims, Section VI-53, Table 6.2.6.3.1.

Carpenter AP. 1979. Determination of tocopherols in vegetable oils. J. Am. Oil Chem. Soc. 56, 668671. https://doi.org/10.1007/bf02660070

Cicero N, Albergamo A, Salvo A, Bua GD, Bartolomeo G, Mangano V, Rotondo A, Di Stefano V, Di Bella G, Dugo G. 2018. Chemical characterization of a variety of cold-pressed gourmet oils available on the Brazilian market. Food Res. Inter. 109, 517-525. https://doi.org/10.1016/j.foodres.2018.04.064

Codex - JOINT FAO/WHO 1999. Food standards programme. In: Codex Alimentarius Commission. Codex standards for named vegetable oils. CXSTAN 210-1999.

Crews C, Hough P, Godward J, Brereton P, Lees M, Guiet S, Winkelmann W. 2006. Quantitation of the main constituents of some authentic grapeseed oils of different origin. J. Agric. Food Chem. 54, 6261-6265. https://doi.org/10.1021/ jf060338y

Dabetic MN, Todorovic MV, Djuricic DI, Antic Stankovic JA, Basic NZ, Vujovic SD, Sobajic SS. 2020. Grape seed oil characterization: A novel 
approach for oil quality assessment. Eur. J. Lipid Sci. Technol. 1900447. https://doi.org/10.1002/ ejlt.201900447

Demirtas I, Pelvan E, Özdemir IS, Alasalvar C, Ertas E. 2013. Lipid characteristics and phenolics of native grape seed oils grown in Turkey. Eur. J. Lipid Sci. Technol. 115, 641-647. https://doi. org/10.1002/ejlt.20120159

Dwyer K, Hosseinian F, Rod M. 2014. The market potential of grape waste alternatives. J. Food Res. 3, 91-106. https://doi.org/10.5539/jfr.v3n2p91

Fagundes Assumpção C, Larroza Nunes I, Alcântara Medonça T, Calixto Bortolin R, Jablonski A, Hickmann Flôres S, Oliviera Rios A. 2016. Bioactive compounds and stability of organic and conventional Vitislabrusca grape seed oils. J. Am. Oil Chem. Soc. 93, 115-124. https://doi. org/10.1007/s11746-015-2742-0

FAOSTAT 2018. FAO Statistical Database, http:// www.fao.org.

Fernandes L, Casal S, Cruz R, Pereira JA, Ramalhosa E. 2013. Seed oils of ten traditional Portuguese grape varieties with interesting chemical and antioxidant properties. Food Res. Inter. 50, 161-166. https://doi.org/10.1016/j. foodres.2012.09.039

Garavaglia J, Markoski MM, Oliveria A, Marcadenti A. 2016. Grape seed oil compounds: Biological and chemical actions for health. Nutr. Metab. Insight. 9, 59-64. https://doi.org/10.4137/NMI. S32910

Gouvinhas I, Machado J, Gomes S, Lopes J, MartinsLopes P, Barros A. 2014. Phenolic composition and antioxidant activity of monovarietal and commercial portuguese olive oils. J. Am. Oil Chem. Soc. 91, 1197-1203. https://doi. org/10.1007/s11746-014-2462-x

Haiyan Z, Bedgood Jr. DR, Bishop AG, Prenzler PD, Robards K. 2007. Endogenous biophenol, fatty acid and volatile profiles of selected oils. Food Chem. 100, 1544-1551.

Jakšić D, Bradić I, Beader M, Ristić M, Popović D, Mošić I, Dodok I. 2019. Vinogradarstvo $i$ vinarstvo Srbije, Studija, Analiza sektora proizvodnje i prerade grožđa i proizvodnje vina. Centar za vinogradarstvo i vinarstvo Niš, Niš, Serbia, pp 9 and 147.

Kiralan M, Çali G, Kiralan S, Özaydin A, Özkan G, Ramada MF. 2019. Stability and volatile oxidation compounds of grape seed, flax seed and black cumin seed cold-pressed oils affected by thermal oxidation. Grasas Aceites 70 (1), e295. https://doi.org/103989/gya.0570181

López-Hortas L, Pérez-Larrán P, GonzálezMuñoz MJ, Falqué E, Domínguez H. 2018. Recent developments on the extraction and application of ursolic acid. A review. Food Res. Int. 103, 130-149. https://doi.org/10.1016/j. foodres.2017.10.028

Lutterodt H, Slavin M, Whent M, Turner E, Yu L. 2011. Fatty acid composition, oxidative stability, antioxidant and antiproliferative properties of selected cold-pressed grape seed oils and flours. Food Chem. 128, 391-399. https://doi. org/10.1016/j.foodchem.2011.03.040

Madawala SRP, Kochar SP, Dutta PC. 2012. Lipid components and oxidative status of selected specialty oils. Grasas Aceites 63 (2), 143-151. https://doi.org/10.3989/gya.083811

Mag TK, Mag T, Reichert RD. 2002. A new recommended calculation of vitamin E activity: Implications for the vegetable oil industry. INFORM 13, 836-839.

Martinez M, Maestri D. 2008. Oil chemical variation in walnut (Juglans regia L.) genotypes grown in Argentina. Eur. J. Lipid Sci. Technol. 110, 11831189. https://doi.org/10.1002/ejlt.200800121

Matthäus B, Spener F. 2008. What we know and what we should know about virgin oils - a general introduction. Eur. J. Lipid Sci. Technol. 110, 597601. https://doi.org/10.1002/ejlt.200800118

Matthäus B. 2008. Virgin grape seed oil: Is it really a nutritional highlight? Eur. J. Lipid Sci. Technol. 110, 645-650. https://doi.org/10.1002/ ejlt.200700276

Oomah BD, Liang J, Godfrey D, Mazza G. 1998. Microwave heating of grapeseed: Effect on oil quality. J. Agric. Food Chem. 46, 4017-4021. https://doi.org/10.1021/jf980412f

Paqout C, Mercier J, Lefort D, Mathieu A, Perron R. 1967. Les Methodes Analitiques des Lipides Simples (in Serbian), Poslovno udruženje proizvođača biljnih ulja, Belgrade, pp. 175-179.

Pardo JE, Fernández E, Rubio M, Alvarruiz A, Alonso GL. 2009. Characterization of grape seed oil from different grape varieties (Vitis vinifera). Eur. J. Lipid Sci. Technol. 111, 188-193. https:// doi.org/10.1002/ejlt.200800052 
Prescha AM, Grajzer M, Dedyk M, Grajeta H. 2014. The antioxidant activity and oxidative stability of cold-pressed oils. J. Am. Oil Chem. Soc. 91, 1291-1301. https://doi.org/10.1007/s11746-014$2479-1$

Radočaj O, Dimić E. 2013. Physico-chemical and nutritive characteristics of selected cold-pressed oils found in the European market. Rivista Ital. Sost. Grasse 90 (4), 219-228.

Rubio M, Alvarez-Orti M, Alvarruiz A, Fernández E, Pardo JE. 2009. Characterization of oil obtained from grape seeds collected during berry development. J. Agric. Food Chem. 57, 28122815. https://doi.org/10.1021/jf803627t

Shinagawa FB, de Santana FC, Torres LRO, Mancini-Filho J. 2015. Grape seed oil: a potential functional food? Food Sci. 35 (3), 399-406. https://doi.org/10.1590/1678-457X.6826

Teh SS, Birch J. 2013. Physicochemical and quality characteristics of cold-pressed hemp, flax and canola seed oils. J. Food Compos. Anal. 30, 2631. https://doi.org/10.1016/j.jfca.2013.01.004

Unusan N. 2020. Proanthocyanidins in grape seeds: An updated review of their health benefits and potential uses in the food industry. J. Funct. Food. 67, 103861. https://doi.org/10.1016/j. jff.2020.103861

Wen X, Zhu M, Hu R, Zhan J, Chen Z, Li J, Ni Y. 2016. Characterisation of seed oils from different grape cultivars grown in China. J. Food Sci. Technol. 53 (7), 3129-3136. https://doi. org/10.1007/s13197-016-2286-9 